\title{
Uma crítica da concepção de política social do Banco Mundial na cena contemporânea
}

\author{
A criticism of the World Bank's concept of \\ social policy in the contemporary scenery
}

Rafael Vieira Teixeira*

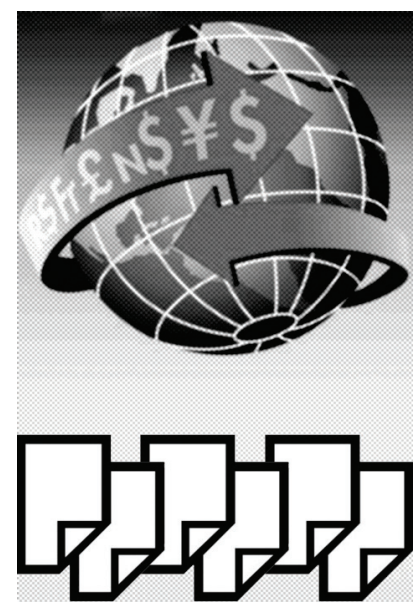

Resumo: O presente artigo reúne os principais elementos que compõem a concepção de política social do Banco Mundial a partir de recentes relatórios publicados sobre o tema pobreza e sociedade na página oficial deste organismo. A ideia central é de que se trata de uma descrição crítica da concepção de política social do Banco, problematizando cada um de seus argumentos mais explícitos com o intuito de desvelar uma intencionalidade organicamente vinculada à classe burguesa. Perspectiva esta que está pautada nos interesses dos segmentos da burguesia articulados em torno de um projeto societário direcionado para a reestruturação capitalista em uma conjuntura de crise estrutural. A concepção de política social do Banco Mundial segue, portanto, uma dimensão profundamente ideológica e política. A utilização, pelo Banco, de instrumentos, como os documentos analisados, para afirmar a hegemonia burguesa na cena contemporânea, atestam que o embate político e ideológico continua presente, explicitando a atualidade da luta de classes.

Palavras-chave: Política Social. Banco Mundial. Questão Social.

\begin{abstract}
This article gathers together the main elements that make up the concept of the World Bank's social policy from recent reportings published about poverty and society in the official page of this organism. The main idea is that it is a critical description of the Bank's concept of social policy, contesting each one of its more explicit arguments to show a perspective organically linked to the middle class. That perspective is based on the interests of those middle class segments tied up to a project for society towards capitalist reorganization in a conjuncture of structural crisis. Therefore, the World Bank's concept of social policy follows a deeply ideological and political dimension. The way
\end{abstract}

* Assistente social da Companhia Docas do Espírito Santo (Codesa); mestre em Política Social pela Universidade Federal do Espírito Santo (Ufes), Vitória/ES, Brasil.E-mail: rafaelufes@yahoo.com.br. 
the Bank uses instruments such as the analyzed documents to assure middle class hegemony in the contemporary scenery certifies that the ideological and political chock is present, which shows that the fight among social classes is still up-to-date.

Keywords: Social policy. World Bank. Social issue.

\section{Introdução}



processo de análise da concepção de política social do Banco Mundial que aqui se propõe foi tratado em minha dissertação de mestrado e perpassa uma abordagem qualitativa de tipo documental, onde os documentos foram selecionados mediante a capacidade de responder à pergunta proposta previamente no projeto de pesquisa. A saber, o que se buscou responder foi qual a concepção atual de política social do Banco Mundial para o Brasil, após o que Salama (2005, p. 12), entre outros, optou por denominar "nova versão do Consenso de Washington", que data de 1995, quando dez outras prescrições foram somadas às consensuadas na primeira reunião de Washington, em 1989.

Nesse sentido, os documentos consultados datam do ano 2000 até 2003, pois esse período foi de grande importância para a consolidação e a experimentação das políticas sociais baseadas na concepção do Banco, principalmente no recorte voltado para a América Latina (Soares, 2000).

Merrien (2007, p. 62), levanta a ideia de um consenso pós-Washington, ressaltando que o reconhecimento dos reais e crescentes impactos sociais dos ajustes estruturais, da fragilidade das instituições e das exigências por políticas sociais antipobreza levaram, desde os anos 2000, a um novo enfoque do ajuste por parte do Banco Mundial.

A ilustração deste novo consenso encontra sua forma típica nos contextos estratégicos de luta contra a pobreza dos anos 2000 em substituição aos planos de ajustamento promovido pelas organizações internacionais nos anos 1980. [...] O Banco Mundial cria um departamento de proteção social cuja filosofia se afasta [...] "do neoliberalismo anterior".

Draibe (apud Behring, 2000) alega que esse período corresponde à segunda fase do neoliberalismo e que é mais propositiva no que tange à gestão pú- 
blica e aos programas sociais. E assim, segundo Soares (2006), nesse contexto o Banco Mundial cumpre seu papel estratégico de intelectual orgânico do grande capital, representando de maneira mais intensiva seus interesses através do discurso da redução da pobreza. Desta forma, diante de uma crise de legitimidade do sistema, há o aprofundamento de medidas neoliberais sob a difusão de uma pseudoproteção social.

A delimitação do universo de documentos para a análise seguiu, além do recorte temporal, um segundo critério, qual seja: relatórios disponibilizados na página eletrônica oficial do Banco para o Brasil relacionados à temática pobreza e sociedade. A matriz neoliberal e a "nova versão" do Consenso de Washington (Salama, 2005) mostram que a inclusão da "atenção" à área social por parte das formulações dos organismos internacionais está diretamente voltada para a redução da pobreza absoluta. Raichelis (2007) argumenta que as intervenções na área social recomendadas por Washington, via organismos multilaterais, concentram-se no atendimento da pobreza extrema, especificamente aquelas situadas abaixo da chamada linha da pobreza.

Desse modo, o universo de documentos consultados para a análise proposta neste estudo contou com quatro relatórios: 1) Estratégias de redução da pobreza no Ceará - 2003; 2) Combate à pobreza rural no Brasil: uma estratégia integrada, v. I - 2001a; 3) O combate à pobreza no Brasil - relatório sobre pobreza, com ênfase nas políticas voltadas para a redução da pobreza urbana, v. I, 2001b; e 4) Vozes dos pobres — Brasil — Relatório nacional — 2000 .

Buscou-se observar, na análise, a processualidade da construção de uma concepção por parte do Banco e dos segmentos da classe dominante que organicamente estão integrados a ele. Em primeiro lugar, foi constatado um reconhecimento, por parte do ideário neoliberal, da existência de pobreza como consequência do próprio ajuste por ele proposto e de sua "persistência" mesmo em períodos de crescimento e desenvolvimento econômico. Isto delimita o primeiro eixo de análise. Em segundo lugar, em decorrência do primeiro eixo, observou-se que houve e há uma tentativa, por parte desse organismo, de conhecer a pobreza e os pobres, as causas de sua existência e o perfil daqueles que vivem na pobreza ou "abaixo" dela. Aqui, o que se verá é uma relação de causa e consequência presente na concepção neoliberal para a explicação da existência da pobreza e da desigualdade. 
Em terceiro lugar, tem-se um eixo central de análise, qual seja, a concepção de política social preconizada pelo Banco Mundial. Nesse eixo, buscam-se explicitar, a partir da processualidade da construção de uma concepção neoliberal, quais serão então seus principais aspectos, as proposições e mesmo a formatação argumentada dessa concepção. Revela-se, nesse sentido, a priorização do econômico em relação ao social (entendidos como partes separadas e autônomas); a focalização das políticas nos extremamente pobres como única forma de intervenção por parte do Estado e a ideia de mitigar (e não erradicar) a pobreza; o papel das transferências mínimas de renda; e a participação e a responsabilização dos indivíduos na superação da condição de pobre, tudo isso compondo o fundamento neoliberal de remercantilização dos direitos e das políticas sociais.

É importante demarcar que a divisão proposta nos eixos de análise tem objetivos pedagógicos tanto para permitir um processo de análise apurado como para facilitar o entendimento do leitor em relação ao que vem a ser a concepção de política social assumida e difundida pelo Banco Mundial. Contudo, o entendimento é que a análise parte da totalidade de um único processo que reúne aspectos históricos, econômicos, políticos e sociais em uma relação orgânica. Nesse sentido, demarca-se um princípio fundante de nossa análise, ou seja, a concepção neoliberal de política social não está dissociada de um projeto de sociedade e de uma concepção de mundo. É, antes, parte constitutiva de um projeto societário defendido pela classe dominante dos países centrais do capitalismo, ou seja, pautado na exploração do trabalho, o que, como será possível compreender mais à frente, em vez de solucionar as contradições inerentes ao próprio sistema capitalista, tenderá, em última instância, ao acirramento de suas contradições, evidenciando cada vez mais e de maneira mais aguda a luta de classes.

\section{Reconhecimento da existência, "persistência" e crescimento da pobreza e da desigualdade}

Por ocasião da própria luta de classes, a reestruturação do sistema capitalista pós-crise 1960/1970 se deu em uma direção determinada pelas concepções societárias da classe dominante, ou seja, como um conjunto de partes integradas 
que compuseram e compõem a reestruturação da produção, passando pela direção macroeconômica marcada pela hegemonia financeira do capital e culminando na remontagem do Estado e no surgimento de novas abordagens ideológicas, que derivam da perspectiva neoliberal. Sendo este um longo debate, cumpre dizer que a perspectiva neoliberal ganha força desde fins da década de 1960 e durante a década de 1970. Assim, através do Consenso de Washington, difunde uma interpretação da realidade após a virada recessiva e aponta um conjunto de ações que deveriam ser (e vêm sendo) adotadas pelos países. Esse fato foi e é emblemático, especialmente no caso dos países latino-americanos (Soares, 2000). Trata-se de uma programática de respostas apresentadas como solução para a crise.

O ajuste proposto pelo Consenso de Washington, então, apresentou-se como a possibilidade de solução para a situação crítica vivida pelos países e suas populações. Vale dizer que esta é a estratégia que representa as interpretações, caracterizações, concepções e interesses das classes dominantes dos países centrais e que foi conscientemente encampada pelas classes dominantes da periferia do sistema capitalista. Assim o receituário neoliberal foi posto em prática. Acontece que os ajustes estruturais, em vez de solucionarem a turbulência da luta de classes vivida na conjuntura de crise, fizeram agravá-la, trazendo soluções (pode-se dizer temporárias) de âmbito econômico-financeiro para as potências centrais do sistema e piorando substancialmente as condições de vida da classe operária do centro e da periferia do sistema.

É nesse contexto que se insere o reconhecimento por parte das classes dominantes dos países centrais: primeiro da existência e da "persistência" da pobreza e da desigualdade. E, logo em seguida, do crescimento destas, mesmo em países que seguiram o receituário proposto a partir de Washington. É, por assim dizer, a obrigação por parte das classes dominantes, de reconhecer o estrago que o próprio ajuste vem causando nas vidas de grandes quantitativos de pessoas, as quais não aceitariam tais condições de maneira submissa por muito tempo. Com isso, afirma-se que o reconhecimento dessa conjuntura foi compulsório e não naturalmente apresentado por parte dos formuladores da ideologia neoliberal, estes sob forte pressão e com a ameaça de perder a hegemonia na direção do processo de reestruturação do sistema.

Assim, o Banco Mundial, como organismo de fomento dos interesses das classes dominantes e disseminador de suas concepções, passou a reconhecer a 
existência, a persistência e o crescimento da pobreza e da desigualdade. Segundo Behring (2000), o Banco, em 1998, já reconhecia a existência de 1,21 milhão de pessoas vivendo com menos de um dólar por dia, situadas predominantemente na Ásia, África e América Latina. Nesse sentido, é emblemático observar a percepção neoliberal desse processo vivido no Brasil, que é apresentada em um dos relatórios analisados neste estudo:

No Brasil, assim como em qualquer outro país latino-americano, reformas orientadas pelo mercado foram implementadas com o objetivo de promover o ajuste estrutural na economia. Estas reformas buscaram liberalizar as relações comerciais, desregulamentar as economias e promover políticas de privatização. [...] As reformas orientadas pelo mercado colocam, no curto prazo, altos custos para as populações urbanas e tendem a acentuar problemas sociais, dado que estas quase sempre implicam reduzir cortes significativos nos gastos públicos e perda de empregos em diversos setores [...]. Os ganhos sistêmicos de eficiência resultantes da exposição à competição internacional deverão surgir no longo prazo. (Banco Mundial, 2000, p. 16)

Ante o exposto, fica claro que as "reformas orientadas pelo mercado" trouxeram altos custos para as populações e que isto tende a ser acentuado devido aos cortes nos gastos sociais. Essa é, pois, uma primeira percepção que se apresenta, isto é, a própria ideologia dominante não pôde se furtar, dado o agravamento das condições de sobrevivência da população (contradição), de reconhecer os impactos sociais negativos do ajuste. Disso resultará, segundo a análise aqui proposta, a criação de uma concepção de política social para responder aos "reconhecidos" problemas, resguardando, contudo, a estrutura da acumulação de capital. A seguir apresentamos algumas citações dos relatórios do Banco que mostram que a pobreza e a desigualdade estão presentes na conjuntura pós-reformas orientadas pelo mercado:

A estabilização dos preços atingidos de 1994 a 1998 causou a redução imediata da pobreza, porém esta ocorreu sem uma redução das desigualdades, as quais aumentaram consideravelmente. A partir de 1997, os ganhos resultantes da estabilização foram reduzidos e a taxa de desemprego quase dobrou em relação aos níveis de 1990. (Banco Mundial, 2000, p. 17)

[...] as perdas da reestruturação industrial tendem a ser maiores do que os ganhos de bem-estar resultantes da eliminação dos níveis de inflação. (Banco Mundial, 2000, p. 16) 
Sob outro referencial, o professor César Benjamin (1997) permite um entendimento bem-fundamentado em relação ao caso brasileiro, que, como visto, teve por parte do Banco Mundial seu reconhecimento como fato, embora os fundamentos e as perspectivas de sua análise sejam de outra ordem.

O real, como todos os outros planos anti-inflacionários aplicados na América Latina nos últimos anos, produz evidentemente um efeito de renda imediato na sua implantação. Quando a sociedade sai de $50 \%$ de inflação ao mês para $1 \%$, há um ganho de renda, que no entanto, não se incorpora à dinâmica do plano. Nenhum economista sério pode considerar que um plano que traz baixo crescimento econômico, alto desemprego e altas taxas de juros possa configurar uma situação macroeconômica que sustente desconcentração de renda. $\mathrm{O}$ efeito distributivo projeta-se nos primeiros meses e não se incorpora organicamente ao funcionamento da economia. A reconcentração está em curso acelerado no país. (Benjamin, 1997, p. 10)

Ou seja, o que se pode deduzir a partir dos textos publicados pelo próprio Banco é que o atendimento às medidas iniciais de ajuste difundidas desde Washington teve um alcance bastante limitado, reduzindo apenas os níveis de pobreza absoluta em contraste com o crescimento dos níveis de desigualdade, e mesmo assim em um curto espaço de tempo, sendo seguido por um forte agravamento do desemprego e dos impactos sociais que ocorrem em decorrência desse cenário. Em suma, o impacto social do ajuste se apresentara de forma tão gritante que a movimentação das classes levou a própria classe dominante a buscar respostas não apenas para os impactos econômicos da crise, mas inclusive os de ordem social e política.

Os relatórios chegam a mencionar os números exorbitantes de pessoas que passaram a sentir o peso dos impactos causados pelo ajuste. E isso considerando apenas os aspectos mais aparentes de uma definição de pobreza extrema medida exclusivamente a partir da renda, sem considerar outras dimensões objetivas e subjetivas.

Dada a linha de pobreza extrema escolhida, o Brasil tem uma taxa de $22,6 \%$. Isso significa que 34,9 milhões de brasileiros vivem em domicílios com uma renda per capita inferior à linha da pobreza. (Banco Mundial, 2001b, p. 4)

Ressalte-se que essa é uma situação bastante grave, considerando que é reconhecida por um dos principais organismos que induziu à adoção das medidas 
ditas de ajuste pelos países. Além do que, se tomadas outras formas de avaliação dos impactos sociais causados por um contexto de ajuste recessivo da magnitude deste, os quantitativos de cidadãos e cidadãs que tiveram piora nos padrões de sobrevivência certamente será muito maior. É importante dizer que a condição de causador dos impactos mencionados não é reconhecida pela classe dominante e nem por seus organismos de difusão teórico-ideológica. Para o Banco as reais causas dos impactos são de outra(s) ordem(s), o que será visto mais adiante.

Assim, o agravamento da questão social não só evidenciou a existência de altos índices de pobreza e desigualdade como denunciou também seu crescimento, o que tem um reconhecimento explícito nos relatórios:

Em termos absolutos, os dados revelam que o número de indivíduos abaixo da linha da pobreza nas regiões metropolitanas cresceram de 10,4 milhões, em 1981 para o patamar de 12,8, milhões em 1989. Em 1994, o número de pessoas abaixo da linha de pobreza atingiu 52 milhões, enquanto os $50 \%$ mais pobres detinham $11 \%$ da renda nacional, atingindo seu ponto mínimo em termos históricos. (Banco Mundial, 2000, p. 17)

Além de assumir que há pobreza e desigualdade em números "inaceitáveis" e de forma crescente, os relatórios reconhecem ainda a insuficiência de combater esses níveis apenas via fortalecimento do mercado e crescimento econômico, evidenciando a contradição do discurso: "O crescimento continuará excluindo alguns indivíduos que estão no degrau mais baixo da distribuição de renda" (Banco Mundial, 2001, p. 21).

Esse é o ponto fundamental na análise deste eixo, ou seja, expressa uma contradição fundamental na concepção que o Banco apresenta: o conjunto de respostas apontadas na forma de políticas integradas visa fortalecer o mercado e toma como principal fundamento a retomada do crescimento econômico. $\mathrm{O}$ fundamento da política social é econômico, e não social. E, com isso, assume a existência de um grupo de pessoas incapaz de se beneficiar desse processo, indivíduos que serão alvo das políticas sociais compensatórias e focalizadas. Contraditoriamente, este grupo não é pequeno, nem transitório. É, ao contrário, crescente em termos absolutos e relativos dentro da própria conjuntura proposta como alternativa de "alívio" da pobreza e da desigualdade.

Há [...] um número expressivo de pessoas extremamente pobres, com baixa escolaridade, que permanecem no limite inferior da distribuição de renda e que 
praticamente não têm sido alcançadas pelo desenvolvimento econômico. Esses pobres - talvez os $10 \%$ a $15 \%$ da população com a menor renda no Brasil frequentemente não conseguem aferir qualquer benefício das oportunidades econômicas [...] (Banco Mundial, 2001b, p. 2)

A extensão do hiato de pobreza (a distância entre a renda média das famílias pobres e a linha de pobreza) é grande, de tal modo que décadas de crescimento sustentado da renda acima dos níveis atuais não conseguiriam retirar da pobreza uma grande parte da população pobre. (Banco Mundial, 2003, p. 42)

Nesse contexto, e de forma bastante explícita, o relatório denominado "Vozes dos Pobres" traz dados empíricos para observar a percepção dos pobres sobre a condição vivida por conta do ajuste no Brasil, e conclui que

há um reconhecimento generalizado de que "os pobres estão se tornando mais pobres e os ricos mais ricos" [e] as pessoas consultadas entendem que as oportunidades para mobilidade social e econômica tem-se reduzido em geral. (Banco Mundial, 2000, p. 28)

O que se busca mostrar até aqui, por meio das citações diretas dos relatórios, é que há, por conta do contexto vivido nos países em que o ajuste estrutural foi adotado, um reconhecido impacto social degradante, que exigiu por parte dos organismos e das classes dominantes dos países centrais não só o seu reconhecimento, mas respostas para as evidentes insuficiências do modelo proposto a partir deles, e que, portanto, punham em ameaça o próprio processo de ajuste em curso.

Obviamente, não querendo perder legitimidade, o ideário neoliberal passou a caracterizar essa situação no sentido de imprimir um conjunto de respostas, agora também de cunho social. Isso para manter a dinâmica macroeconômica que, por um lado, privilegia cada vez mais os segmentos da classe dominante atrelados ao movimento de financeirização, e que por outro, no seu anverso, continua submetendo cada vez mais pessoas a condições desumanas de sobrevivência, as quais serão, portanto, o alvo das políticas sociais públicas propostas nesta concepção. Iamamoto (2001) conclui que, sob esta ótica "a questão social produzida e reproduzida ampliadamente tem sido vista [...] enquanto 'disfunção' ou 'ameaça' à ordem e à coesão social", o que leva a um apontamento do trato de suas expressões contemporâneas de maneira fragmentada, 
visando o controle e o restabelecimento dos fatores de coesão, típica de uma abordagem organicamente intolerante a transformações na estrutura da produção e distribuição de riqueza e poder.

De outro lado, subsidiado pelas análises da mesma autora, o presente estudo reafirma a questão social como "indissociável do processo de acumulação e dos efeitos que produz sob o conjunto das classes trabalhadoras, o que se encontra na base da exigência de políticas sociais públicas" (Iamamoto, 2001, p. 11). Assim, reitera-se que a existência e o crescimento dos níveis de pobreza e desigualdade têm fundamentos estruturais historicamente situados na fase tardia do sistema capitalista, e que, portanto, têm no próprio processo de reestruturação da sociabilidade burguesa a sua reprodução ampliada.

Seguindo a proposta de análise deste estudo, vejamos o que os relatórios trazem sobre as causas e as características da pobreza, entendendo que esta percepção é de suma importância para o entendimento das políticas formuladas pelo Banco e seus parceiros.

\section{Caracterização da pobreza e perfil dos pobres}

Como os próprios relatórios demonstram, a existência da pobreza e da desigualdade e seu crescimento em termos absolutos e relativos é inegável (mesmo em países que seguiram à risca as recomendações iniciais de Washington e até mesmo em países que tiveram taxas de crescimento econômico razoáveis desde a virada recessiva de 1970). Isso exige construir uma explicação para tal existência, e bem como a caracterização da população que vivencia as situações de pobreza extrema nesta conjuntura.

O Banco Mundial, nos quatro documentos analisados, apresenta resultados de estudos feitos sobre a pobreza no Brasil. Há menção sobre procedimentos avaliativos para as políticas sociais voltadas para esse público, bem como sobre características mais gerais da pobreza urbana e rural no país. Os estudos trazem prioritariamente uma abordagem quantitativa e se baseiam em uma matriz neoliberal para a análise dos dados coletados, como pode ser evidenciado no trecho que segue de um dos documentos:

[...] definição de pobreza abrange renda e consumo insuficientes, o não atendimento de necessidades básicas como educação, saúde, nutrição e moradia, inseguran- 
ça e risco, bem como falta de voz e de poder. Para fins de análises quantitativas, contudo, este relatório adotou uma definição bem mais restrita de pobreza, como sendo apenas insuficiência de renda ou consumo. [...] Este relatório também não tratou de questões ligadas de forma mais ampla às desigualdades de renda, patrimônio e oportunidades [...] (Banco Mundial, 2001, p. 1; grifos meus)

Na caracterização acima é possível extrair a concepção política e ideológica do Banco no que se refere aos sujeitos e às relações entre classes. Ou seja, a própria restrição da definição de pobreza sinaliza um esvaziamento da complexidade do tema.

Embora exista uma significativa heterogeneidade entre os pobres, a estrutura da pobreza apresenta algumas características gerais nítidas. A maior influência se encontra nas áreas rurais, onde cerca de três quartos da população vive na pobreza [...], [há] também uma concentração da pobreza entre os jovens. (Banco Mundial, 2003, p. 26)

Aqui novamente a abordagem é quantitativa e faz uma caracterização da pobreza como sendo heterogênea, predominantemente rural e concentrada entre os jovens. É perceptível que a pobreza, nesse caso, tem sua caracterização a partir de si mesma, dissociada de outros fatores socioeconômicos e políticos.

[A pobreza] deve-se, principalmente, às influências históricas e às condições externas[:] herança histórica representada por um ciclo vicioso de desvantagens, no qual uma estrutura desigual de trabalho e de ativos físicos, de educação e capital humano, de poder e cultura, bem como de vulnerabilidade, interagiram de modo a perpetuar a desigualdade de renda. [E] consequências externas adversas devido às condições gerais do Brasil, especialmente com respeito ao lento crescimento, à instabilidade macroeconômica [...] (Banco Mundial, 2003, p. 9; grifos meus)

A "herança histórica" a que se refere o documento parte de uma "estrutura desigual" a qual não tem suas causas problematizadas e que por sua vez é geradora de um "ciclo vicioso de desvantagens" que interage de forma a "perpetuar a desigualdade". Seguindo a linha de pensamento do relatório, afirma-se que essa condição é agravada pelas "consequências externas adversas", de cunho macroeconômico, que no caso do Brasil seriam da ordem do lento crescimento e da instabilidade. 
Essa afirmativa descrita a partir do relatório de 2003 suscita duas reflexões que podem ser percebidas na caracterização da pobreza proposta pelo Banco. A primeira diz respeito à inversão no que se refere às causas da pobreza. Parte do pressuposto de que a pobreza tem inúmeras causas sem, contudo, propor uma reflexão aprofundada sobre estas. Recorrentemente observam-se menções à pobreza como algo dado e autônomo, sendo que a caracterização passa a se ater a aspectos mais de cunho descritivo do que propriamente explicativos, como foi ressaltado.

O aumento da pobreza é produto da interação entre crescimento e desigualdade - quanto mais desigual uma sociedade menos a população pobre tende a se beneficiar do crescimento (Banco Mundial, 2003, p. 23)

[...] os altos níveis de desigualdade reduzem o impacto do crescimento sobre o declínio da pobreza e a desigualdade [...] (p. 37)

Caberia indagar qual, então, é a causa da desigualdade? Na análise proposta pelo presente estudo, a desigualdade econômica, social e política deriva exatamente da própria lógica contraditória do sistema capitalista, sendo, portanto, uma consequência dele. Nesse sentido, comparando com a concepção do Banco, que nesse entendimento tenta autonomizar as expressões da questão social, recorramos a Iamamoto $(2009$, p. 11-12) para apreender a questão social:

Esse modo de vida implica contradições básicas: por um lado, a igualdade jurídica dos cidadãos livres é inseparável da desigualdade econômica derivada do caráter cada vez mais social da produção, contraposta à apropriação privada do trabalho alheio. Por outro lado, ao crescimento do capital corresponde a crescente pauperização relativa do trabalhador. Essa é a lei geral da produção capitalista, que se encontra na gênese da "questão social" nessa sociedade.

A segunda reflexão apresenta-se em consequência da percepção da primeira, ou seja, a partir da autonomização da pobreza, passa-se a culpabilizar os pobres pela sua condição e pela própria reprodução da pobreza.

Em primeiro lugar, as culturas politica e social de desigualdades são normalmente parte das sociedades onde não há equidade [...] Em segundo lugar, os padrões de adaptação dos grupos de pobres ou de excluídos às condições adversas podem, frequentemente, levar a práticas cujas consequências são negativas para o seu próprio desenvolvimento - como no caso do aumento da cultura de drogas e 
violência em muitas partes urbanas do Brasil [...]. (Banco Mundial, 2003, p. 31; grifos meus)

[...] são muito importantes os esforços paralelos para atingir os jovens [...], a fim de lhes proporcionar oportunidades para romper o ciclo vicioso ao qual os seus parentes mais velhos estão presos. (Banco Mundial, 2001a, p. VII)

Assim, pode-se perceber que a caracterização autônoma da pobreza leva a um entendimento de que os próprios pobres têm responsabilidade sobre sua condição, o que aponta para a busca de alternativas com o intuito de "ajudá-lo" para que ele próprio possa romper com o "ciclo vicioso". Essa percepção traz um indicativo de que a política social proposta pelo Banco como resposta à conjuntura de existência e crescimento da pobreza e da desigualdade estará baseada na responsabilização do indivíduo na busca por alternativas de superação de suas condições.

A mesma reflexão que se apresenta neste eixo de análise também sugere que o reconhecimento da existência da pobreza e da desigualdade não leva necessariamente à busca por sua superação, como também não aborda necessariamente sua caracterização e suas causas de maneira ampla e profunda, podendo inclusive, como se mostra o caso do Banco Mundial, dissimular causas e argumentar a existência da pobreza como algo natural e ainda atribuir aos indivíduos a culpa por sua situação de pobreza e miséria, bem como a reprodução desta condição.

É nesse contexto que, como dito, o conteúdo dos documentos estudados carrega uma concepção de sociedade fundada na perspectiva neoliberal, o que culminará, como veremos, na formatação de uma concepção de política social específica que vem sendo recomendada pelo Banco aos países, via acordos, projetos e programas de desenvolvimento, metas internacionais etc. Portanto, uma vez sendo esboçado o que, segundo a análise proposta, fundamenta a concepção de política social do Banco Mundial no atual contexto, passemos especificamente à sua análise.

\section{A concepção de política social do Banco Mundial}

Inicialmente, é preciso lembrar que a política social, nessa perspectiva, nasce do reconhecimento da existência da pobreza e da desigualdade em escala 
ampliada a partir do ajuste estrutural em curso (embora como algo natural e fragmentado), passando por seu estudo e por sua caracterização, o que remete ao entendimento que esse tipo de resposta por parte do Estado deve ser redimensionado, partindo de uma forte crítica aos gastos sociais assumidos dentro do chamado pacto keynesiano, de onde se conclui que o gasto social público só é legítimo se for eficazmente focalizado para aliviar situações de extrema pobreza.

Chama-se o Estado a responsabilizar-se pelo novo modelo macroeconômico em curso, direcionando sua atuação para a restauração do capital, em detrimento de seu papel "mediador civilizador" da sociedade, característico do pacto keynesiano (Behring, 2000). Nesse campo, a atuação na área social é vista como onerosa e desnecessária, sendo fomentados rigorosos critérios de focalização como pressupostos para a concepção das políticas sociais.

Contudo, antes da reflexão sobre a defesa intransigente desse organismo em relação à máxima focalização das políticas sociais nos extremamente e comprovadamente pobres, faz-se necessária uma discussão acerca da relação entre o econômico e o social, que é apresentada nos documentos e que, tal qual preconiza a perspectiva de sociedade neoliberal, coloca o desenvolvimento econômico como prioritário em relação ao desenvolvimento social, sendo este último uma consequência daquele. Assim, para a perspectiva do Banco Mundial, o desenvolvimento social é uma consequência do desenvolvimento econômico. Uma vez feitos os encaminhamentos e tomadas as decisões corretas em função de um desenvolvimento econômico via mercado autorregulado, as intervenções de cunho social serão necessárias como resposta a eventuais falhas na sociabilidade pelo mercado, onde aqueles que não conseguirem se beneficiar dessa lógica poderão ser usuários de políticas sociais, desde que comprovem sua necessidade.

\section{Econômico x social}

É essencial para este estudo demarcar que a prioridade pelo desenvolvimento econômico via mercado e o desenvolvimento social como consequência, o que coloca a política social em um lugar de complemento aos desvios causados pelo mercado, não se configura como a única perspectiva existente de sociedade, desenvolvimento econômico e social, e nem de política social. Uma perspectiva radicalmente inversa a essa se mostra não só possível, mas clara- 
mente necessária e urgente, e será fruto de uma decisão política coletiva da classe trabalhadora.

De início, vale menção a uma afirmativa da professora Elaine Behring (2000, p. 31), na qual a "hipótese central é a incompatibilidade estrutural entre acumulação e equidade". Igualmente, no debate sobre a política social, Iamamoto (2001, p. 22) afirma que:

As estratégias para o enfrentamento da questão social têm sido tensionadas por projetos sociais distintos, que presidem a estruturação e a implementação das políticas sociais públicas e que convivem em luta no seu interior. Vive-se uma tensão entre a defesa dos direitos sociais e a mercantilização do atendimento às necessidades sociais $[\ldots]$

O livro das professoras Angela Ferriol e Rita Castiñeras e do professor Goran Therborn (2004) ilustra, a partir de uma comparação das políticas sociais em Cuba e na Suécia, a existência de uma experiência de políticas sociais baseadas no desenvolvimento social como prioritário, como valor fundamental, o que relega ao desenvolvimento econômico uma função subordinada aos interesses da maioria da população. Assim, a produção de bens e serviços fica voltada para o atendimento das necessidades e interesses coletivos da população. Utilizando parâmetros oficiais de mensuração dos indicadores formulados pela Cepal, mostram que a prioridade pelo bem-estar integral da população em Cuba faz com que esse país, mesmo passando por uma forte escassez de recursos, atinja indicadores sociais mais elevados do que os países mais desenvolvidos do mundo capitalista. Ressaltam, nesse estudo, a universalidade e a gratuidade como pontos fortes de programas de segurança alimentar e nutricional, moradia e infraestrutura, saúde, educação, cultura, esportes, previdência etc.

Nesse sentido, como se pode perceber, as reflexões de fundo crítico à lógica capitalista constituem o referencial teórico que orienta a análise aqui proposta. Dito isso, retomemos a análise da concepção neoliberal de política social presente nos relatórios do Banco. Partimos da explicitação da prioridade pelo desenvolvimento econômico em detrimento do social, o que explicitará a função e o alcance da política social nessa perspectiva:

O governo deveria continuar promovendo o ajuste fiscal sustentável e de alta qualidade, pois esta é uma forma de assegurar a estabilidade macroeconômica e 
um custo decrescente para o capital. A estabilidade macroeconômica e o capital mais barato estimularão o investimento e o crescimento sustentado, que, por sua vez, levarão a uma redução da pobreza. Dada a estreita relação entre ajuste fiscal, crescimento e redução da pobreza, é importante enfatizar que o empenho contínuo do governo no sentido do ajuste fiscal constitui um pré-requisito essencial para uma redução mais efetiva da pobreza. Especificamente, na medida em que as despesas sociais de alta qualidade permanecem protegidas dos cortes fiscais, os possíveis impactos negativos da política de ajuste a curto prazo poderão ser mais do que compensados pelos benefícios a longo prazo da estabilidade, do crescimento e da redução de pobreza produzidos por essa mesma política de ajuste. (Banco Mundial, 2001b, p. 14 e 15; grifos meus)

Essa passagem de um dos relatórios demonstra claramente a perspectiva neoliberal recomendada pelo Banco em defesa dos ajustes estruturais. Como se pode perceber, a receita é a seguinte: adotar o ajuste fiscal para assegurar o controle macroeconômico em benefício do capital, inclusive reduzindo seus custos; esse controle permitirá que o mercado seja retomado como prioritário no contexto das relações socioeconômicas. $\mathrm{O}$ que, segundo essa perspectiva, beneficiará a todos, até mesmo os pobres. Então a primeira medida proposta para reduzir a pobreza é a estabilidade macroeconômica para garantir a primazia do mercado. À frente, essa mesma passagem afirma que os possíveis impactos negativos do ajuste serão compensados pelo benefício a longo prazo e que esses impactos podem ser minimizados com políticas sociais de "alta qualidade" (leia-se bem focalizadas), mas que a estabilidade e o crescimento serão de tal maneira positivos que se justifica a adoção do ajuste.

Em todas as circunstâncias o capital é priorizado, seja em função da necessidade de estimular o crescimento econômico para o benefício de todas as classes - "Se o crescimento do Brasil for acelerado, é quase certo que isso trará benefícios de modo geral [...]" (Banco Mundial, 2003, p. 42) —, seja como medida de combate à pobreza, em função do seu correto funcionamento:

Essencialmente seria muito difícil obter, no Brasil, uma redução significativa da pobreza [...] sem um estável crescimento econômico geral. (Banco Mundial, 2001a, p. I)

Estudos feitos em âmbito internacional e também estudos específicos para o Brasil confirmam uma forte ligação entre crescimento econômico e redução de pobreza. (Banco Mundial, 2001b, p. 13) 
Entretanto, é perceptível também nos próprios relatórios que a prioridade pelo crescimento econômico é muito mais uma questão de vontade política do que propriamente de uma alternativa única em termos econômicos. O trecho citado abaixo revela que a eliminação da pobreza dependeria de uma radical transformação na sociabilidade do capital, preço este que, na perspectiva do Banco, parece inviável. Uma socialização da riqueza da amplitude necessária para erradicar a pobreza não é condizente com os interesses dos segmentos de classe aos quais o Banco Mundial está atrelado e representa interesses. Desta forma, parece mais plausível para esta perspectiva a resignação ao alívio da pobreza:

[...] o Brasil talvez não pareça precisar de crescimento para pôr fim à pobreza. Entretanto, o custo de se eliminar a pobreza através de transferências ficará muito mais alto do que nos levariam a crer os cálculos [...] Por outro lado, há dúvidas quanto à viabilidade política de se fazer uma redistribuição de renda em larga escala. [...] Diferentemente do que acontece com as transferências, o crescimento torna o alívio da pobreza algo muito mais palatável politicamente. (Banco Mundial, 2001b, p. 13; grifos meus)

Aliás, é emblemático ressaltar que recorrentemente, nos relatórios, diferentes termos são utilizados para pôr de lado a ideia de erradicação da pobreza, como, por exemplo, alívio, mitigação, redução etc. Isso mostra como a decisão de erradicar a pobreza não é uma questão econômica e nem a prioridade para a classe dominante, o que permitirá, também, perceber o alcance das ações propostas dentro desta perspectiva. No documento de 2001b (p. 9), o Banco Mundial descarta completamente a opção de erradicação da pobreza através da redistribuição da riqueza: "o cenário de erradicação [...] da pobreza é claramente inviável e insustentável. Essa estratégia exigiria transferências anuais de R \$ 27 bilhões para os pobres".

Com isso, apresenta três outras opções pautadas na priorização do desenvolvimento econômico, com taxas de crescimento variantes entre $2 \%$ e $6 \%$ para que o Brasil atinja a meta de reduzir a pobreza extrema em 50\% até 2015 . Segundo esse mesmo relatório, reduzir a taxa de pobreza extrema em 50\% significa ter em 2015 cerca de $11 \%$ da população do país vivendo nessas condições. O próprio relatório reconhece a existência de não menos que $22 \%$ da população nacional vivendo abaixo da linha da pobreza, e considera plausível e satisfatório que em quinze anos metade dessa população ascenda à condição de "apenas" pobres, permanecendo a outra metade nas mesmas condições. 
O professor César Benjamin (1997) se indigna com tal constatação dizendo que é inaceitável uma conjuntura como essa e que é necessária uma postura política clara que reverta esse quadro de total concentração de riquezas. Para ele, como para a perspectiva aqui assumida neste estudo, a prioridade deve pautar-se nas demandas humanas e sociais dos indivíduos, ainda que o preço político e econômico desta postura seja caro. Como Paiva (2000), defende que a concepção de política social deva orientar-se pela relevância social e por critérios de equidade. No relatório fica evidente que não se pretende assumir tal postura, o que evidencia o vínculo orgânico dessa perspectiva com os segmentos que vêm se beneficiando historicamente no processo de acumulação de riqueza e poder. Para sintetizar nossa análise, vale trazer, mais uma vez, a contribuição crítica da professora Marilda Iamamoto (2001, p. 23), que reitera que a perspectiva de sociedade sob a inspiração neoliberal:

[...] subordina os direitos sociais à lógica orçamentária, a política social à política econômica, em especial às dotações orçamentárias [...]. Observa-se uma inversão e uma subversão: em vez do direito constitucional impor e orientar a distribuição das verbas orçamentárias, o dever legal passa a ser submetido à disponibilidade de recursos. São as definições orçamentárias [...] que se tornam parâmetros para a implementação dos direitos sociais [...]

\section{Focalização na extrema pobreza}

Sob o argumento da eficiência, da eficácia e da responsabilidade com os gastos públicos fomenta-se a ideia de que a política social deva estar voltada para os segmentos extremamente pauperizados, desprovidos de condições de acesso aos "benefícios" da concorrência e do mercado.

Os investimentos públicos e os programas [...] devem ser submetidos a uma análise econômica rigorosa. As alocações dos recursos [...] devem ser revistas e reformuladas para assegurar uma focalização social mais efetiva dos programas e também maior eficiência dos investimentos. (Banco Mundial, 2001b, p. 15)

Para Paiva (2000), este é um argumento tendencioso que alega que os recursos até existem, mas são mal alocados. Com isso defende-se que os recur- 
sos públicos devam ser utilizados para ações exclusivamente voltadas para os pobres, resguardando o atendimento das necessidades dos demais segmentos à via privada, por meio da compra. Para Mandel (apud Behring, 2000), tem-se uma supercapitalização da esfera da reprodução.

Raichelis (2007) considera que a partir desse discurso o que se busca é uma dualização das políticas sociais, onde, de um lado, o Estado (com participação de segmentos da sociedade civil) provê os mínimos para os excluídos ou incluídos muito precariamente no mercado, com uma pobre política para os pobres. De outro lado, amplia-se a venda de prestações aos trabalhadores formais em várias escalas de preços e padrões de qualidade, no que se denomina remercantilização dos direitos.

Nesse sentido, abre-se um largo espaço para que os serviços sociais se tornem mercadorias altamente lucrativas, estimulando a produção, a circulação e o consumo em um período marcado por forte recessão.

Uma focalização melhor requer abordagens diferentes, dependendo de cada programa. Para programas universais, tais como educação, saúde e serviços urbanos, a focalização das despesas públicas pode ser melhorada [...]. A [...] universalização dos serviços [...] equivale (sic), na realidade a focalizar os pobres na hora de se planejar a expansão dos serviços. [...] Para programas de seguro, tais como aposentadorias e seguro-desemprego, as contribuições e os benefícios poderiam ser fixados de forma a que se recorresse a recursos públicos apenas no caso de transferências focalizadas nos pobres. (Banco Mundial, 2001b, p. 28)

Soares (2006, p. 81) apresenta uma lista de vários programas ${ }^{1}$ financiados pelo Banco Mundial em que todos, de alguma maneira, afirmam "a necessidade de racionalizar e concentrar os recursos sociais para o enfrentamento da pobreza". Segundo Pereira (2000) essa é uma noção que reduz à assistência aos extremamente pobres a noção de proteção social, com a função de evitar que

1. "Dentre os diversos programas do governo brasileiro que foram ou são financiados pelo referido Banco, podemos destacar: Programa Bolsa Família; Programa Nacional DST e Aids I, II e III; Programa de Apoio à Reforma Previdenciária nos Municípios; Projeto de Vigilância e Controle de Doenças — Vigisus II; Projeto de Assistência Técnica para a Previdência Social; Programa de Apoio à Reforma dos Sistemas Estaduais de Previdência - Parsep; Projeto de Reforço à Reorganização do Sistema Único de Saúde; Sistema Nacional de Vigilância em Saúde — Vigisus; Programa Saúde da Família. [...] Todos eles fundamentados na ‘Estratégia de Assistência ao País”' (Soares, 2005, p. 81). 
segmentos socialmente necessitados caiam para baixo de uma linha de pobreza legitimada pela sociedade.

Castiñeras, Ferriol e Therborn (2004) alegam que para os neoliberais esta é uma perspectiva de equidade moralmente aceitável, ou seja, assegurar que a população se situe acima da linha da pobreza, obtendo um mínimo necessário à sobrevida, expresso nas estratégias focalizadas na redução da pobreza absoluta, a partir da qual, em contrapartida, se abre o caminho para a legitimação incondicional do direito à propriedade e da aceitação irrestrita das diferenças no acesso à riqueza e à renda. Sobre o papel moral que ocupa o discurso em torno da necessidade de redução da pobreza extrema, Iamamoto (2001, p. 25) acrescenta que:

Salienta-se a coesão social e um forte apelo ao bem comum, discurso esse que ocorre em paralelo à reprodução ampliada das desigualdades, da pobreza e da violência. Estas tendem a ser naturalizadas, onde o horizonte é a redução de seus índices mais alarmantes.

Sobre a focalização proposta pelo Banco Mundial, vejamos a síntese da professora Raquel Soares (2006, p. 86):

Defendendo uma equidade pervertida, o Banco Mundial recupera o discurso do enfrentamento da pobreza com a finalidade de defender a focalização [...] sem explicitar seus reais interesses de ampliação do mercado privado. [...] a pobreza [...] é utilizada [...] como elemento mistificador dos fundamentos ideopolíticos nas mais diversas áreas, dentre elas, a seguridade social.

Além do mais, a focalização é vista como um instrumento de garantia para que o mercado não seja desestimulado por uma postura "comodista" dos usuários dos serviços públicos. Assim, sugere-se que a focalização nos extremamente pobres seja acompanhada por um alto grau de seletividade e por pagamento de benefícios rigorosamente baixos (esta noção tem forte relação com a caracterização da pobreza e dos pobres analisada antes). Some-se a isso que, sempre que possível, essas políticas focalizadas devem ser acompanhadas de contrapartidas por parte dos usuários, na forma de trabalho, para garantir que não haja, de fato, acomodações. 
[...] os esquemas de obras públicas, ou uma remuneração baixa para o trabalho (workfare) pode se constituir em um instrumento eficaz para lidar com essas dificuldades. (Banco Mundial, 2003, p. 56)

Uma rede de segurança social também pode garantir um nível básico de consumo para aqueles que são incapazes de se beneficiar das oportunidades criadas pelo crescimento e pelos investimentos sociais. [...] Embora programas bem concebidos de rede de segurança possam retirar um grande contingente de pessoas carentes da pobreza [...] se não forem cuidadosamente concebidos, ameaçam criar armadilhas de pobreza e estímulos indesejáveis. (Banco Mundial, 2001b, p. 21; grifos meus)

Desse modo, observa-se que a concepção de política social do Banco Mundial, no que tange a focalização, expressa de forma clara seus objetivos de fortalecer prioritariamente o funcionamento do mercado, ainda que isso passe pela aceitação da existência de pessoas vivendo na condição de pobreza absoluta. A resposta a ser dada a pessoas nessas condições não poderá, em hipótese alguma, passar pelo enfraquecimento da concorrência entre os indivíduos sob a ameaça de ser desestimulante ao trabalho e fomentador da ociosidade. Nesse sentido, as políticas sociais de caráter público, além de se voltarem apenas para os extremamente pobres, não lhes pode oferecer uma condição digna de vida, pois isso somente pode ser alcançado via mercado. Com isso nega-se o acesso a qualquer que seja a política social dentro de uma perspectiva de direto social e humano no atendimento das necessidades. A retórica da eficiência e da eficácia acompanha esta concepção com o intuito de dissimular a existência de uma clara negação da dignidade humana em favor dos interesses do capital. Em todas as afirmativas citadas, e em outras tantas que surgem nos textos dos documentos, não se trata da focalização em uma perspectiva reparadora de violações históricas aos direitos humanos. Aqui a focalização traz apenas a necessidade de não ultrapassar aqueles(as) que vivem na condição de miseráveis que não são capazes de tirar proveito dos "benefícios" do mercado.

Assim, mais uma vez argumentando em favor dos interesses do capital, o Banco Mundial avança em sua programática concepção rumo à operacionalização mais adequada da focalização que defende. Ou seja, a forma mais eficaz, segundo o Banco, para se atingir os extremamente pobres sem prejudicar o mercado e, ao contrário, fortalecê-lo, é via transferência direta de renda aos pobres. Renda essa que deve, como visto, pautar-se em valores absolutamente baixos. 


\section{Transferências diretas de renda}

Programas envolvendo dinheiro e vales são preferíveis à prestação de serviços em espécie, a menos que estes últimos possam ser justificados em termos de melhor focalização [...]. Em alguns casos, a substituição de serviços em espécie pelo financiamento de vales pode ser uma forma efetiva de aumentar a transparência, a liberdade de escolha do consumidor, a concorrência e a eficiência interna. (Banco Mundial, 2001b, p. 29)

Como se pode observar, o argumento em defesa da transferência direta de renda não visa prioritariamente as necessidades dos sujeitos, e sim o fortalecimento do mercado, através do consumo, da concorrência e da eficiência na circulação. Aqui as intervenções sociais não abarcam quaisquer aspectos qualitativos, pautados na interação entre sujeitos, na construção de processos de formulação e gestão, na participação como forma de inserir novos atores no processo decisório e como espaço pedagógico de construção de uma nova cultura.

Trata-se tão somente de repassar aos pobres uma renda baixa com o objetivo de atingir indicadores que demonstrem que determinado número de sujeitos não vive mais abaixo da chamada linha da pobreza. Essa perspectiva visa obter ganhos quantitativos no curto prazo exatamente para tentar resgatar a legitimidade do processo de acumulação em um período marcado por profunda recessão e por fortes impactos sociais causados pelos ajustes: “As transferências de renda constituem a única maneira rápida de reduzir a pobreza no contexto de taxas de crescimento moderadas [...], contribuindo para proteger as pessoas mais pobres das armadilhas da pobreza" (Banco Mundial, 2003, p. 53).

Raichelis (2007, p. 16) chama a atenção para o fato de que o argumento em favor das transferências como resposta urgente para um momento transitório de ajuste se trata, na realidade, de um discurso que quer esconder uma questão estrutural e potencialmente permanente:

O modelo de proteção social para pobres, no qual se inserem os programas de transferência de renda, é uma resposta necessária frente às urgências sociais, mas pontual e transitória a uma questão estrutural, portanto, persistente. Responde ao presente, atendendo necessidades imediatas, adota uma perspectiva reducionista da pobreza como expressão monetária, mas não ataca os seus determinantes es- 
truturais, especialmente os relacionados à política econômica e ao modelo de desenvolvimento, mantendo inalterados os índices de desigualdade no Brasil [...]

Sobre esta questão, Castel (2004) concorda dizendo que o transitório vem se tornando permanente sem sequer atingir o que se propõe, ou seja, integrar/ inserir os sujeitos beneficiários das políticas de transferência nos mercados. Os sujeitos "permanecem lá onde estão". Prova disso é o aumento do número absoluto da demanda nos últimos vinte anos por respostas que aliviem a pobreza absoluta.

É preciso perceber ainda de que forma a pobreza aparece como uma armadilha em que os pobres caem, por algum motivo. O que, pelos argumentos, não parece estar associado ao período recessivo, nem tampouco ao processo de acumulação. Assim, conclui-se que a única saída são as transferências de renda. Contudo, como já foi exposto, não se trata de transferências capazes de garantir uma transformação em direção ao fim das desigualdades de renda e acesso à riqueza. Não obstante, o acesso a esses programas passa por uma comprovação da condição de pobreza extrema, no que se pode considerar um real atestado de pobreza, conforme os clássicos princípios liberais que tratavam as expressões da questão social de modo a punir moralmente os que necessitavam das intervenções sociais (Behring e Boschetti, 2006).

Segundo a lógica de focalização das ações públicas naqueles que, comprovadamente, forem incapazes de se prover por meio da concorrência em um mercado cada vez mais acirrado, as transferências diretas de rendas rigorosamente baixas surgem como o componente principal da concepção de política social do Banco Mundial (2003, p. 52):

As transferências de renda para indivíduos ou famílias representam um componente essencial da política social [...] As transferências consistem (sic) na parte mais expressiva da política social [:] são de crescente importância [...] em vista da maior preocupação com o risco e com os prejudicados pelas mudanças [...] e pelos avanços tecnológicos. Uma política coerente de transferência de renda é complementar a uma estratégia orientada para o mercado. As transferências de renda são utilizadas por duas razões: para proteger as pessoas dos choques adversos e para determinados grupos em tempos normais.

Assim, uma política social ancorada na transferência mínima de renda aos comprovadamente pobres caracteriza a concepção do Banco e de sua matriz 
teórica e ideológica. É enfática a afirmativa de que essa é uma maneira coerente de se unir mercado e política social. Ou seja, em tempos "normais" de expansão do mercado as transferências servem para aqueles que não se beneficiaram do progresso. E em tempos adversos, de choque, de catástrofes e/ou de forte recessão, as transferências focalizadas se justificam ainda mais. Além do mais, conforme afirmam os documentos, essa não apenas é uma estratégia coerente e eficaz, mas é também a única possível.

Reforça-se, portanto, o papel do Banco Mundial como produtor e difusor da ideologia neoliberal (Soares; 2006). Com isso, é possível ter maior clareza sobre o que escondem os fundamentos desta perspectiva, ou seja, uma deslegitimação dos direitos sociais via desresponsablização do Estado na sua garantia. Ao reduzir o papel do Estado sob o argumento da ineficiência das suas políticas e da sua incapacidade de provisão, defende uma perspectiva de política social que se distancia de uma noção de diretos e retorna, na forma de um conservadorismo renovado, ao mercado autorregulado e à ideologia do controle das classes populares. É o que Castel (2004) chama de controle do processo de desagregação, num cenário em que a tensão entre interesses antagônicos de classe atinge dimensões agudas e potencialmente transformadoras.

\section{Participação/responsabilização da sociedade civil}

A renovação da perspectiva conservadora, de cunho neoliberal, evidencia que a descentralização com desresponsabilização do Estado abre uma lacuna que intencionalmente responsabiliza a sociedade civil na provisão das necessidades sociais da população. Para Draibe (apud Behring, 2000), esta perspectiva compõe um trinômio que articula focalização, privatização e descentralização.

Embora as orientações gerais possam estar claras, a formulação específica das políticas - e uma implementação ainda mais eficaz - dependerá criticamente da interação entre instituições públicas, empresas privadas, comunidades, grupos políticos, agentes da sociedade civil etc. (Banco Mundal, 2003, p. 66)

Esse processo de responsabilização da sociedade civil via descentralização é seguido de um discurso que dá relevância à participação. Como o conjunto das concepções do Banco, a participação segue uma perspectiva neoliberal, o 
que, como vem sendo afirmado, se opõe substancialmente à concepção assumida pelo presente trabalho. A existência de concepções antagônicas de participação advindas de matrizes teórico-ideológicas opostas coloca no debate em torno da política social a necessidade de uma atenção redobrada aos discursos de instituições como o Banco Mundial.

Raichelis (2007, p. 13) alerta para uma confluência perversa: “[...] é que ambos os projetos exigem o fortalecimento da sociedade civil, uma sociedade civil ativa e propositiva, mas em direções opostas e antagônicas". A perspectiva defendida pelo Banco tem como pressuposto da participação uma regressão do papel do Estado e a redução da esfera pública e dos diretos sociais, fazendo um chamado à participação no sentido de transferir o custeio e a execução das políticas sociais para a sociedade civil:

Acompanhando a onda de descentralização que usualmente a democratização traz, os governos locais se tornaram um importante palco para inovações. A década de 90 inaugurou a montagem de um conjunto considerável de novas estruturas institucionais nos governos locais, através dos quais os processos de participação e deliberação na formulação e implementação de políticas públicas se tornaram presentes. (Banco Mundial, 2000, p. 19; grifo meu)

Paiva (2000, p. 86) alega que os processos de gestão das políticas sociais que acompanham a descentralização na perspectiva neoliberal, orientada por princípios de máxima focalização e eficiência no gasto social, inferem uma participação fundada no apoio, na colaboração e na aceitação, não se tratando "de participação política, e sim de colaboração dos beneficiários no planejamento e na implementação dos programas". Esta crítica alerta para uma perspectiva legitimadora na qual há pouca partilha com a sociedade civil do processo decisório.

Além disso, segundo o Banco, o custeio e a força de trabalho podem e devem ser gradativamente transferidos para a provisão pelos indivíduos e grupos sociais. Mais uma vez vale trazer citação do relatório:

Exemplo de sucesso - Projeto São José: “[...] características inovadoras do programa: (a) participação de mão de obra comunitária de baixo custo; (b) utilização de tecnologias adequadas e de baixo custo; e (c) aquisição de material e a supervisão dos trabalhos feitas pelos próprios beneficiários. Embora os ganhos estima- 
dos para cada família seja pequeno em relação à defasagem de renda [...] e, portanto insuficiente para deslocar as famílias para um posição acima das linhas de pobreza mais utilizadas, o ganho por beneficiário, mesmo assim, pode proporcionar melhoras significativas na qualidade de vida”. (Banco Mundial, 2003, p. 28)

O documento faz questão de sublinhar que se trata de uma experiência de sucesso, pois economiza gastos relativos à força de trabalho, compra de materiais e ainda com custo tecnológico, sem contar que reconhece que o alcance é extremamente limitado do ponto de vista da defasagem de renda das famílias. É emblemático ao ressaltar sua estratégia como um ganho voltado para o fortalecimento da participação. Este tipo de participação é recorrentemente evidenciada pelo Banco como uma iniciativa profícua, na qual os indivíduos são estimulados a perceber o valor de seu trabalho por meio da atuação voluntária em programas e projetos que visam atender a necessidades que deveriam, conforme a Constituição Federal de 1988, ser garantidas pelo Estado. O ponto positivo, para a perspectiva deste organismo situa-se na possibilidade de estimular a formação da capacidade laboral e empreendedora.

[...] uma estratégia de redução da pobreza deveria ter como objetivo principal o incentivo à população pobre das comunidades para criar o seu capital social [...] para que se engajem na gestão de seus próprios esforços de desenvolvimento local. (Banco Mundial, 2001a, p. 24)

Além do mais, observa-se que a responsabilização da participação carrega consigo uma noção de que a condição de necessitado remete ao indivíduo sua explicação, de onde também individualizada a superação da situação de pobreza. O estímulo a esforços locais e à criação de capital social é uma palavra de ordem na concepção de política social neoliberal. É algo que está tão seguramente imbricado na corrente de valor dessa perspectiva que, em alguns casos, quando os indivíduos não partem desse entendimento, os intelectuais chegam a ficar surpresos com a incapacidade de alguns de solucionarem os próprios problemas:

De modo geral, os grupos mostraram uma surpreendente descrença em sua capacidade de resolver problemas por si mesmos [ou seja,] solucionados pela comunidade sem uma ajuda externa. [...] existem poucos exemplos de problemas solucionados efetivamente pelas próprias comunidades. (Banco Mundial, 2000, p. 44 e 45; grifos meus) 
No trecho abaixo, as políticas sociais efetivas devem ser concebidas numa perspectiva de ajudar as famílias, subentendendo-se que não se trata de garantir a elas o acesso a direitos. Observe-se também que a parceria, nesse sentido, é relegada à condição de ajuda, excluindo-se os processos decisórios e participativos em termos de elaboração:

O senso de dependência em relação às (sic) instituições é [...] elevado [e] a parceria do governo e das famílias é necessária. Políticas sociais efetivas são concebidas como necessárias para ajudar as famílias. (Banco Mundial, 2000, p. 46)

Para Montaño (apud Soares, 2006), trata-se de uma "autorresponsabilização dos necessitados", pois segmentos carentes da população são responsabilizados pela execução e pelo financiamento de políticas, serviços e programas. Vale ressaltar, com isso, que a função principal dessa perspectiva de participação é de oferecer balizas ideológicas para afirmar a prioridade incondicional de garantir a retração do Estado na provisão das políticas sociais, resguardando, portanto, um nicho considerável para o mercado por meio da já mencionada supercapitalização, além de direcionar os gastos estatais para os interesses do grande capital (financeiro). Vejamos outra citação que fortalece a presente análise:

A participação pode reduzir significativamente o custo das políticas em diversas áreas. Contribuições em espécie feitas pelos beneficiários, participação de ONGs, fiscalização de empreiteiros e aquisições feitas por associações comunitárias, podem reduzir custos significativamente. [...] uma participação genuína pode estimular o desenvolvimento do capital social que, por sua vez, pode capacitar os pobres a elevarem seu bem-estar [...] (Banco Mundial, 2001b, p. 23)

Iamamoto (2001) afirma que a abertura para a atuação da sociedade civil carrega consigo tanto a transferência de responsabilidades do Estado aos sujeitos, no que tange à provisão dos serviços, quanto um crescente nicho de mercantilização dos direitos, que os transfere da dimensão pública para a esfera do privado. Assim, segundo a autora, a responsabilização dos sujeitos, através da inclusão de um terceiro setor no atendimento das necessidades sociais, é permeada por uma lógica de direito privado, distinta daquela que desde a Constituição Federal de 1988 regulamentou essas necessidades como de direito público. E conclui que: 
Uma progressiva mercantilização do atendimento das necessidades sociais vem ocorrendo com a privatização das políticas sociais. Nesse processo, os serviços sociais deixam de expressar direitos sociais, metamorfoseando-se em atividades de outra natureza, inscrita no circuito de compra e venda de mercadorias, em detrimento dos direitos sociais de cidadania, que, em sua necessária dimensão de universalidade requer a ingerência do Estado. O substitutivo são os direitos atinentes à condição de consumidor [...]. Quem julga a pertinência e a qualidade dos serviços prestados são os que, através do consumo, renovam sua necessidade social. (Iamamoto, 2001, p. 26)

Em suma, concordamos com Iamamoto e com Soares (2006), quando alegam que a participação da sociedade civil é usada para legitimar o esvaziamento dos direitos sociais, fomentando-se uma equidade pervertida onde o Banco retoma o discurso do alívio à pobreza para defender a focalização, sem, contudo, evidenciar seu compromisso com a ampliação da prestação privada de serviços sociais.

\section{Conclusão}

Com isso conclui-se que na concepção de política social do organismo aqui estudado, cada um dos eixos tem um papel político-ideológico: 1) A começar pela noção de que a prioridade para o desenvolvimento social é o crescimento econômico, o que reafirma a defesa do ajuste estrutural; 2) passando pela focalização nos extremamente pobres como forma de aliviar (e não erradicar) a pobreza, numa perspectiva de assegurar os fatores de coesão da sociedade capitalista; 3 ) onde tem papel estratégico a noção de transferências de rendas (mínimas) aos comprovadamente pobres. Esta noção assume a condição de elemento central da concepção de política social do Banco, tanto porque permite um resultado de curto prazo como resposta aos agudos problemas vividos por grandes segmentos da população, quanto porque é condizente com o princípio de que as políticas devam ser orientadas pelo e para o mercado, o que, portanto, tem na renda um fator estimulador das economias em localidades extremamente pobres além de atribuir aos indivíduos a condição de protagonistas na superação de sua condição de pobreza. E é assim que o transitório se torna permanente. 
Soma-se ainda 4) a noção de participação difundida em paralelo à desresponsabilização do Estado no provimento das necessidades sociais, funcionando como um chamamento moral a todos no compromisso com os desfavorecidos. Noção esta que oculta a readequação do papel do Estado como agente estratégico na manutenção e retomada dos princípios da sociedade burguesa, atuando na esfera macroeconômica em favor do grande capital e, por consequência (mas de maneira dissimulada), em desfavor das classes que têm apenas a força de trabalho para vender. Com a referida noção de participação abre-se ainda um grande nicho para a atuação do setor privado na venda de serviços sociais, em caráter "complementar", que adquire proporções gigantescas em todos os campos em que as necessidades sociais puderem adquirir a dimensão de mercadorias altamente lucrativas.

Desta forma, evidencia-se, na perspectiva deste estudo, a concepção de política social presente nos relatórios oficiais do Banco Mundial. A partir de uma descrição crítica buscou-se apresentar os elementos estratégicos (e que são imbricados) que compõem a argumentação do Banco e que balizam as diretivas recomendadas por esta instituição aos mais diferentes países, com especial influência nos países latino-americanos. É preciso reiterar que a descrição feita ressalta não só a caracterização dos elementos estratégicos para a concepção de política social do Banco, mas principalmente seu laço orgânico com a teoria neoliberal e com os segmentos de classe aos quais está representando. Além do mais, é preciso dizer que muitos estudos, como por exemplo, o da professora Raquel Soares (2006) vêm demonstrado que as recomendações permanecem seguidas à risca pelos governos nacionais. Segundo demonstra em seu trabalho, a força ideopolítica neoliberal difundida a partir do Banco Mundial é tal que sua concepção vem sendo seguida à risca pelos governos na condução de uma gama de políticas sociais. Obviamente a comprovação empírica desta concepção não é objeto e nem pretensão do presente estudo. Busca-se apenas afirmar que a importância de se conhecer tal concepção tem fundamentos históricos que são estruturais e conjunturais, além de necessários para pensar a política social na cena contemporânea.

Artigo recebido em maio/2010 - Aprovado em ago./2010 


\section{Referências bibliográficas}

BANCO MUNDIAL. Estratégias de redução da pobreza no Ceará. 2003. Disponível em: <http://web.worldbank.org/>. Acesso em: 4 set. 2008.

. Combate à pobreza rural no Brasil: uma estratégia integrada, 2001a. v. 1. Disponível em: <http://web.worldbank.org/>. Acesso em: 4 set. 2008.

. O combate à pobreza no Brasil: relatório sobre pobreza, com ênfase nas políticas voltadas para a redução da pobreza urbana, 2001b. 2. Disponível em: $<$ http://web. worldbank.org/>. Acesso em: 4 set. 2008.

. Vozes dos pobres: Brasil. Relatório Nacional, 2000. Disponível em: <http:// web.worldbank.org/>. Acesso em: 4 set. 2008.

BEHRING, Elaine Rossetti. Principais abordagens teóricas da política social e da cidadania. Capacitação em Serviço Social e política social: o trabalho do assistente social. Módulo 3. Brasília: UnB, Centro de Educação Aberta Continuada a Distância, 2000. p. 19-40.

; BOSCHETTI, Ivanete. Política social: fundamentos e história. São Paulo: Cortez, 2006.

BENJAMIN, César. Reforma, nação e barbárie. In: CONSELHO FEDERAL DE SERVIÇO SOCIAL. Revista Inscrita, Rio de Janeiro/Brasília, ano 1, n. 1, nov. 1997.

BRAZ, M.; NETTO, J. P. Economia política: uma introdução crítica. São Paulo: Cortez, 2006. (Biblioteca Básica do Serviço Social, v. 1.)

CASTEL, R. As transformações da questão social. In: WANDERLEY, M. B.; BOGUS L.; YAZBEK, M. C. (Orgs.). Desigualdade e questão social. 2. ed. São Paulo: Educ, 2004. p. 235-272.

CASTIÑEIRAS, Rita; FERRIOL, Angela; THERBORN, Göran. Política social: el mundo contemporaneo y las experiencias de Cuba y Suecia. La Habana: Instituto Nacinal de Investigaciones Económicas, 2004.

IAMAMOTO, Marilda Villela. A questão social no capitalismo. Temporalis. Revista da Associação Brasileira de Ensino e Pesquisa em Serviço Social (ABEPSS), Brasília, ano II, n. 3, jan./jun. 2001.

O Serviço Social na cena contemporânea. Serviço Social: direitos sociais e competências profissionais. Curso de Capacitação a Distância. Brasília: Conselho Federal de Serviço Social/CFESS; UnB/Centro de Educação Aberta Continuada a Distância/Cead, 2009. 
MERRIEN, François-Xavier. Estados providência e o futuro - uma releitura crítica de pesquisas recentes. In: CARVALHO, D. B. B. de; DEMO, P.; SOUZA, N. H. B. de (Orgs.). Novos paradigmas da política social. Brasília: UnB, Programa de Pós-graduação em Política Social, Departamento de Serviço Social, 2002.

MERRIEN, François-Xavier. Em direção a um novo consenso pós-Washington na América Latina? In: CARVALHO, Denise B. B.; DINIZ, Débora; STEIN, Rosa H.; de SOUZA, Perci C. Política social, justiça e direitos de cidadania na América Latina. Brasília: UnB, Programa de Pós-Graduação em Política Social, Departamento de Serviço Social, 2007.

PAIVA, Beatriz Augusto. Reflexões sobre a pesquisa e processos de formulação e gestão. Capacitação em Serviço Social e política social: o trabalho do assistente social. Módulo 4. Brasília: UnB, Centro de Educação Aberta, Continuada a Distância, 2000. p. 79-94

PEREIRA, Potyara Amazoneida Pereira. A metamorfose da questão social e a reestruturação das políticas sociais. Capacitação em Serviço Social e política social. Brasília: Cead/UnB, 2000.

RAICHELIS, Raquel. Gestão pública e cidade - notas sobre a questão social em São Paulo. Serviço Social \& Sociedade, São Paulo, ano XXVIII, n. 90, jun. 2007.

SALAMA, P. Abertura e pobreza, qual abertura? Revista da Sociedade Brasileira de Economia Política, Rio de Janeiro, ano 8, n. 17, dez. 2005.

SOARES, L. T. Os custos sociais do ajuste neoliberal na América Latina. São Paulo: Cortez, 2000.

SOARES, Raquel Cavalcante. Banco Mundial e a contrarreforma do estado brasileiro: as inflexões da responsabilização da sociedade civil no programa de DST/Aids. Temporalis. Revista da Associação Brasileira de Ensino e Pesquisa em Serviço Social (Abepss), Brasília, ano VI, n. 12, p. 79-91, jul./dez. 2006. 